\title{
Changing trends of anaemia prevalence among female medical students in a metropolitan setting: Assessment through self-grading and haematological parameters
}

\author{
Arisha Salman', Shamim A. Qureshi' ${ }^{2}$, Muhammad Bilal Azmi ${ }^{3}$
}

\begin{abstract}
Objective: To determine the trend of anaemia prevalence among female medical students (FMS) through self-grading along haematological parameters and its association with their nutritional indicators.

Methods: This cross-sectional study was conducted at a public sector health university of Karachi among FMS from April to September 2016. After written informed consent, 216 FMS were assessed for height and weight, for nutrition habits by calculating minimum dietary diversity for women (MDD-W) and anaemia status by self-administered validated self-grading anaemia assessment questionnaire (SGAAQ). The haematological parameters were examined in venous blood sample on Sysmex (XN-3000). The data was analysed using IBM SPSS software version 24. Association between anaemia and nutritional indicators was determined by Chi-square and considered significant when $\mathrm{p}<0.05$.

Results: Anaemia prevalence was 31\% with highest frequency among obese (56\%) and 29\% FMS achieved MDD-W. The mean SGAAQ score, $\mathrm{Hb}(\mathrm{g} / \mathrm{dl}), M C V(\mathrm{fl}), \mathrm{MCH}(\mathrm{pg})$ and Ret-He $(\mathrm{pg})$ differed significantly $(\mathrm{p}=$ $<0.001)$ between anaemic and non-anaemic students. The mean $\mathrm{Hb}(\mathrm{g} / \mathrm{dl})$ level was significantly higher for FMS who scored MDD-W $>5(p=0.04)$.

Conclusion: Malnutrition and anaemia co-exist despite appropriate awareness of anaemia among FMS. It was associated with self-assessment of anaemia and BMI groups but not with dietary diversity in the present study.
\end{abstract}

KEYWORDS: Anaemia, Body mass index, Female medical students, Minimum dietary diversity for women.

How to cite this:

doi: https://doi.org/10.12669/pjms.36.7.2793

Salman A, Qureshi SA, Azmi MB. Changing trends of anaemia prevalence among female medical students in a metropolitan setting: Assessment through self-grading and haematological parameters. Pak J Med Sci. 2020;36(7):1533-1538.

doi: https://doi.org/10.12669/pjms.36.7.2793

This is an Open Access article distributed under the terms of the Creative Commons Attribution License (http://creativecommons.org/licenses/by/3.0), which permits unrestricted use, distribution, and reproduction in any medium, provided the original work is properly cited.

1. Dr. Arisha Salman, MBBS.

Lecturer,

Department of Biochemistry,

2. Dr. Shamim A. Qureshi, Ph.D.

Professor, Department of Biochemistry,

University of Karachi,

Karachi, Pakistan

3. Dr. Muhammad Bilal Azmi, Ph.D.

Assistant Professor,

Department of Biochemistry,

1,3: Dow University of Health Science,

Karachi, Pakistan

Correspondence:

Dr. Shamim A. Qureshi, Ph.D.

Professor, Department of Biochemistry,

University of Karachi,

Karachi, Pakistan.

E-mail: qureshi29@live.com

* Received for Publication:

* Revision Received:

* Revision Accepted:
April 4, 2020

August 8, 2020

August 15, 2020

\section{INTRODUCTION}

Anaemia is defined as haemoglobin $(\mathrm{Hb})$ below established sex, age, and pregnancy-specific cut-off values in a population influenced by age, smoking and altitude. ${ }^{1}$ The World Health Organization (WHO) estimates anaemia affects $30-55 \%$ young adults worldwide. ${ }^{2}$ The National Nutrition Survey (NNS 2018) reported that anaemia affects $41.7 \%$ of non-pregnant women in Pakistan. Iron deficiency anaemia remains the number one cause of years lived with disability (YLDs) in Pakistan from 2005 to 2016.3 Sindh has the highest iron deficiency anaemia prevalence of $23.8 \%$ (NNS 2018). Jawed, S. et al., reported $33 \%$ anaemia frequency in 2017 increasing up to $69 \%$ in 2018 among female medical student (FMS), thus emerging as a moderate to major public health problem. ${ }^{4}$ 
Anaemia has a multifactorial etiology categorized as nutritional, infectious and genetic factors. It is detected by haemoglobin $(\mathrm{Hb} \mathrm{g} / \mathrm{dl}$ ) level lower than cut-off value. Reticulocyte Hemoglobin (Ret-He pg) is an early indicator of iron deficiency even before anemia manifestation. ${ }^{5}$ The risk of anaemia is also patterned by level of education, societal practices, socio-economic status especially in women and children. ${ }^{6}$ The general symptoms and signs result from inadequate tissue oxygenation including fatigue, dyspnea on exertion progressing to breathlessness at rest, vertigo, headache and rapid heart-beat and pallor skin, conjunctivae, palms and nail beds. Despite access to better health facilities female medical students (FMS) are at increased risk of anaemia due to their physiological responses to challenging situations, low iron stores, menstrual losses and inadequate food intake. ${ }^{7}$

Malnutrition is claimed to be the most common and preventable cause of anaemia. NNS 2018 shows the double burden of malnutrition (DBM) with almost one in eight adolescent girls being underweight along $11.4 \%$ and $5.5 \%$ prevalence of overweight and obesity. The assessment and improvement of nutritional indicators like BMI and dietary diversity of FMS can reduce chances of anaemia among them. ${ }^{8}$ This DBM and anaemia challenges the FMS to contribute their fullest potential to the welfare of society and their families. Therefore, aim of the study was to assess the anaemia status through self-grading and its haematological markers and its association with BMI and dietary diversity in FMS.

\section{METHODS}

This is a cross-sectional observational study conducted from April to September 2016 at public sector health university in Karachi. Ethics approval was obtained from Institutional Review Board/ Ethics Review Committee, Dow University of Health Sciences, Karachi via letter No. IRB-659/ DUHS/Approval/2016/209. Written informed consent was taken from all participants and briefed about the nature of the study and survey instrument. The sample size was computed using online Rao Soft Sample size calculator by adjusting the margin of error (d) at significance level of $5 \%$, confidence level at $95 \%$, and population size at 20000, with response distribution at $50 \%$. The recommended sample size was 377 subjects. By adding the probability of $35 \%$ drop out of subjects, the final sample size was equivalent to 500. The FMS aged 18 to 24 years were enrolled in study by random sampling,100 FMS from each study year in systematic manner. Every third FMS was enrolled after random selection of first one. The enrolment of in study is shown in Fig.1. The participants were excluded from the study who refused to participate, treated for any type of anaemia in past, family history of haemoglobinopathy or blood transfusion in the previous 24 weeks, worm infestation, menstrual disorders, malignancy, known communicable and non-communicable diseases and pregnancy.

Phase I: The Self-Grading Anaemia Assessment (SGAA) score was calculated by using a structured and pre-tested questionnaire on anaemia status of subjects. At the end of questionnaire total score was calculated. The adequate dietary micronutrient intake of FMS was assessed using "Minimum Dietary Diversity-Women" (MDD-W) score. It is based on the number of food groups consumed prior day or night. Total ten food items divided into three groups were used : Plant-based (green leafy vegetables, fruits and fresh juices), animal based (eggs and poultry, red meat, milk and fish) and staple based (cereals and whole grains). FMS scoring a MDD-W $<5$ were labelled as having low dietary diversity while MDD-W > 5-10 as having high dietary diversity. ${ }^{9}$ Height $(\mathrm{m})$ and weight $(\mathrm{Kg})$ were measured to calculate BMI. ${ }^{10}$

Phase II: Venipuncture was performed according to Standard Operating Procedures (SOPs) and five $\mathrm{ml}$ blood sample was collected in ethylenediamine tetra acetic acid (EDTA) containing (purpletoped) tube. Anticoagulated whole blood samples were analyzed for complete blood count within

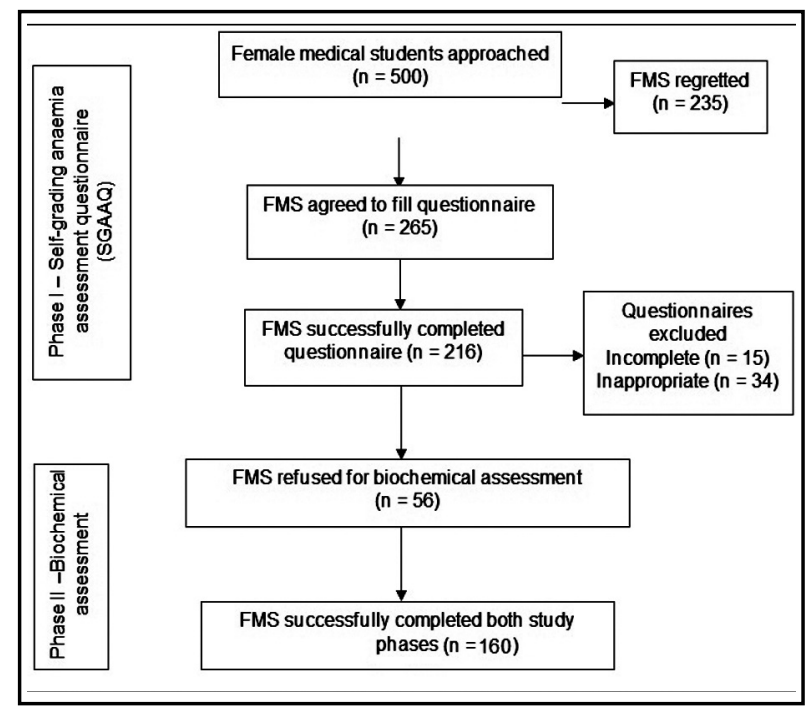

Fig.1: Enrollment of female medical students in study phase I and II. 
two hours of their collection after calibration and control on automated analyzer, Sysmex (XN3000). The parameters studied were Haemoglobin $(\mathrm{Hb}) \mathrm{g} / \mathrm{d}$, Mean cell volume (MCV) fL, Mean Cell Haemoglobin $(\mathrm{MCH}) \mathrm{pg}$, Reticulocyte Haemoglobin (Ret-He) pg. The -2SD value of mean $\mathrm{Hb}$ level of non-anaemic students with normocytic normochromic red cell morphology was used (13.02 $\mathrm{g} / \mathrm{dL} \pm$ 0.62) to establish the reference range for anemia detection. The lower cut -off value was $11.7 \mathrm{~g} / \mathrm{dL}$ and higher cutoff value was $14.2 \mathrm{~g} / \mathrm{dL}$. Peripheral blood film was prepared to study cell morphology within four hours of sample collection and examined initially with /X 10 followed by /X40 under Olympus CX21 microscope. To confirm the quality of peripheral blood smears, the films were examined twice by principal investigator and an expert laboratory technologist. Cronbach's Alpha was also determined for the consistency among the responses of the study tool. Descriptive data was expressed as mean and standard deviation. The mean values were compared by Mann Whitney $U$ test for two independent groups, Kruskal Wallis test to compare multiple groups as data was not distributed normally. Association between anaemia and nutritional indicators was determined by Chi-square and considered significant when $p<0.05$. Data was analyzed by using Statistical Package for Social Sciences (SPSS) version 24.

\section{RESULTS}

The mean age of the study participants was 19.40 years $\pm 1.00(95 \% \mathrm{CI}: 19.26-19.53)$ and mean $\mathrm{Hb}$ value was $12.1 \mathrm{~g} / \mathrm{dL} \pm 1.44$ (95\% CI:11.86 12.32). The frequency of anaemic students was 2.3 times more than the non-anaemic FMS. The SGAAQ score and $\mathrm{Hb}$ level of FMS was compared at individual, household and community level. The SGAAQ score was significantly different between age groups, study year while birth order for both i.e, SGAAQ score and $\mathrm{Hb}(\mathrm{g} / \mathrm{dl})$ of FMS (Table-I).

The mean SGAAQ score was significantly low $(p=0.03)$ between non-anaemic and anaemic FMS indicating appropriate awareness of anaemia. The haematological markers of anaemic FMS were below the lower cut-off value except WBC reflecting that adequate anaemia awareness did not improve their anaemia markers (Table-II).

The average BMI of the study participants was $20.31 \mathrm{~kg} / \mathrm{m} 2$ (95\% CI:19.85-20.77); underweight (BMI <18.5 kg/m2), overweight (BMI 23-27.5 $\mathrm{kg} / \mathrm{m} 2$ ) and obesity (BMI>27.5 kg/m2) were reported in $33.7,18.5$ and $3.7 \%$ of the study participants respectively, however the frequency of anaemic overweight/obese FMS was higher than underweight anemic FMS. The significant association of BMI groups of FMS with their anaemia status $(p=0.04)$ was determined but the mean MDD-W score did not differ significantly

Table-I: SGAAQ score and $\mathrm{Hb}(\mathrm{g} / \mathrm{dL})$ based distribution of significant baseline characteristics among female medical students (n 216).

\begin{tabular}{|c|c|c|c|c|c|}
\hline \multicolumn{2}{|c|}{ Characteristics } & $\begin{array}{c}\text { No. of participants } \\
n(\%)\end{array}$ & $\begin{array}{c}\text { SGAAQ score } \\
\text { Mean } \pm \text { S.D } n 216\end{array}$ & $\begin{array}{c}\text { No. of participants } \\
n(\%)\end{array}$ & $\begin{array}{c}H b(g / d L) \\
\text { Mean } \pm \text { S.D } n 160\end{array}$ \\
\hline \multirow{4}{*}{ Age (years) } & $<19$ & $36(16.5)$ & $86.94 \pm 9.78^{a}$ & $23(14)$ & $12.08 \pm 1.15$ \\
\hline & $19-20$ & 157 (72.3) & $81.93 \pm 11.94^{\mathrm{b}}$ & 117 (73) & $12.15 \pm 1.43$ \\
\hline & $>20$ & $24(11)$ & $81.83 \pm 13.50^{c}$ & $19(12)$ & $11.71 \pm 1.85$ \\
\hline & $\mathrm{p}$ value & & $0.03^{*}$ & $p$ value & 0.46 \\
\hline \multirow{3}{*}{$\begin{array}{l}\text { Year of } \\
\text { study }\end{array}$} & First & $131(61)$ & $84.80 \pm 9.45^{\mathrm{a}}$ & $89(55.6)$ & $12.1 \pm 1.49$ \\
\hline & $\begin{array}{l}\text { Other than } \\
\text { first year }\end{array}$ & $85(40)$ & $80.88 \pm 12.5^{b}$ & $71(44.4)$ & $11.65 \pm 1.43$ \\
\hline & $\mathrm{p}$ value & & $0.01^{*}$ & $\mathrm{p}$ value & 0.05 \\
\hline \multirow{3}{*}{ Birth order } & $\leq 2$ & $141(65)$ & $83.97 \pm 10.4^{\mathrm{a}}$ & $97(60.6)$ & $12.4 \pm 1.27$ \\
\hline & $>2$ & 75 (35) & $80.44 \pm 11.45^{b}$ & $63(39.3)$ & $11.6 \pm 1.57^{\mathrm{b}}$ \\
\hline & $\mathrm{p}$ value & & $0.02 *$ & $\mathrm{p}$ value & $<0.001^{* *}$ \\
\hline
\end{tabular}

${ }^{a}$ superscript other than ${ }^{\text {a }}$ denotes significantly low value; SGAAQ: Self-Grading Anaemia Assessment Questionnaire, $\mathrm{Hb}$ : Haemoglobin, Mann Whitney U test was used to compare two groups. Kruskal Wallis test was used to compare more than two groups. 
Table-II: Self-graded anaemia(SGAAQ) and haematological parameters of female medical students with respect to anaemic status $(n=160)$.

\begin{tabular}{llccc}
\hline \multirow{2}{*}{ Variables } & & \multicolumn{2}{c}{ Anaemic Status } & $p$ value \\
\cline { 3 - 4 } & & Non-anaemic $(n$ 111) & Anaemic $(n$ 49) & 0.03 \\
SGAAQ & SGAAQ score & $83.6 \pm 12$ & $79.0 \pm 13$ & $<0.001$ \\
Hematological parameters & $\mathrm{Hb}(\mathrm{g} / \mathrm{dL})$ & $12.8 \pm 0.6$ & $10.4 \pm 1.0$ & $<0.001$ \\
& $\mathrm{MCV}(\mathrm{fL})$ & $86.0 \pm 6.2$ & $76.8 \pm 9.9$ & $<0.001$ \\
& $\mathrm{MCH}(\mathrm{pg})$ & $28.0 \pm 2.5$ & $23.5 \pm 3.9$ & $<0.001$ \\
& Ret-He $(\mathrm{pg})$ & $29.2 \pm 1.5$ & $28.2 \pm 1.9$ & $<0.001$ \\
\hline
\end{tabular}

All values expressed as mean \pm S.D, SGAAQ: Self-Grading Anaemia Assessment Questionnaire,

$\mathrm{Hb}$ : Haemoglobin, MCV: Mean cell volume, MCH: Mean cell haemoglobin,

Ret-He: Reticulocyte Haemoglobin, WBC: White blood cell.

Table-III: Distribution of BMI categories of female medical students by their anaemic status and dietary diversity score $(n=160)$.

\begin{tabular}{llcccc}
\hline & & \multicolumn{3}{c}{ Anaemia status } & \multicolumn{1}{c}{ MDD-W } \\
\cline { 3 - 5 } & & Non anaemic n $(\%)$ & Anaemic n $(\%)$ & Total $n$ & Mean \pm S.D \\
\hline BMI $^{\mathrm{a}}$ & Normal weight & $50(69)$ & $22(31)$ & 72 & $1.90 \pm 1.39$ \\
& Underweight & $45(79)$ & $12(21)$ & 57 & $2.45 \pm 1.76$ \\
& Overweight & $9(60)$ & $6(40)$ & 15 & $1.85 \pm 1.83$ \\
& Obese & $7(44)$ & $9(56)$ & 16 & $2.23 \pm 1.85$ \\
p value & & & $0.03^{\mathrm{b}}$ & $0.24^{\mathrm{c}}$ \\
\hline
\end{tabular}

${ }^{a}$ Asian -specific Body mass index11: Underweight <18.5, Normal weight :18.5 - 22.9, Overweight: 23 - 26.9, Obese $\geq 27$, MDD-W: minimum dietary diversity. ${ }^{\mathrm{b}}$ Chi-square test used to compare proportions, ${ }^{\mathrm{c}}$ Kruskal Wallis test was used to compare more than two groups.

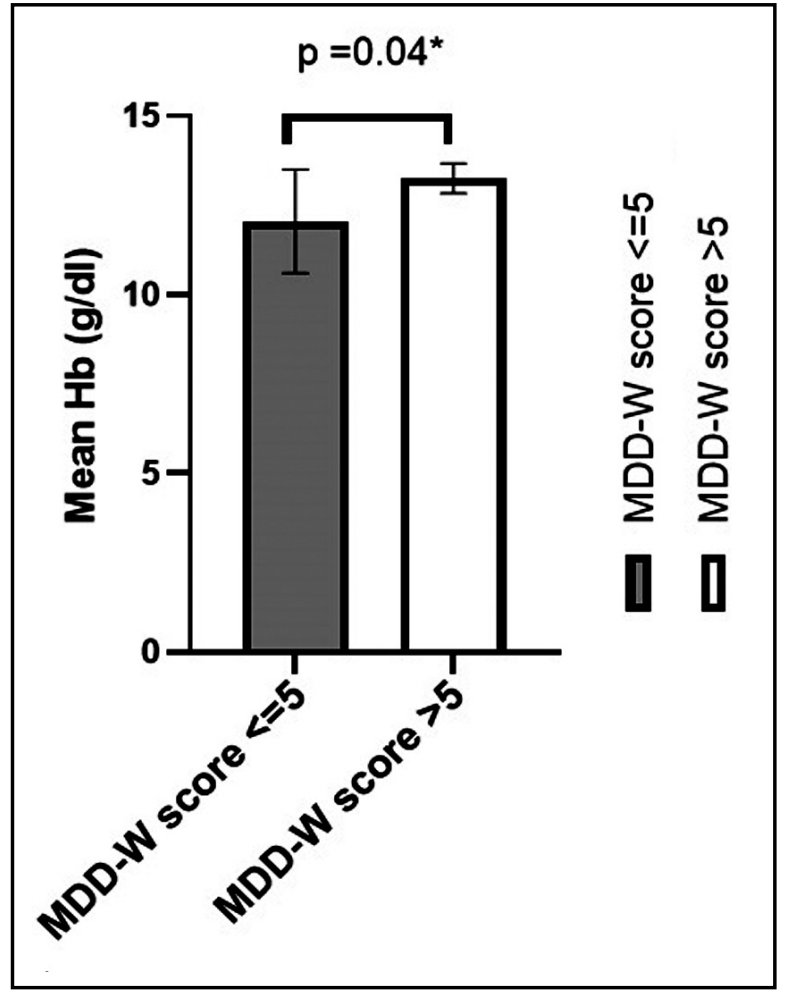

Fig.2: Mean $\mathrm{Hb}(\mathrm{g} / \mathrm{dl})$ level of Female Medical Students by MDD-W score $\mathrm{n}=160$.
(Table-III). However, significant low mean $\mathrm{Hb}$ (g/dl) was observed for FMS with MDD-W $\leq 5$ than those with MDD-W>5(p=0.04) (Fig.2).

The food groups consumption on previous day by FMS was not associated significantly with their anaemia status. However, the frequency of micronutrient dense plant and staple diet intake was more among non-anaemic FMS than those anaemic but meat and poultry intake was slightly

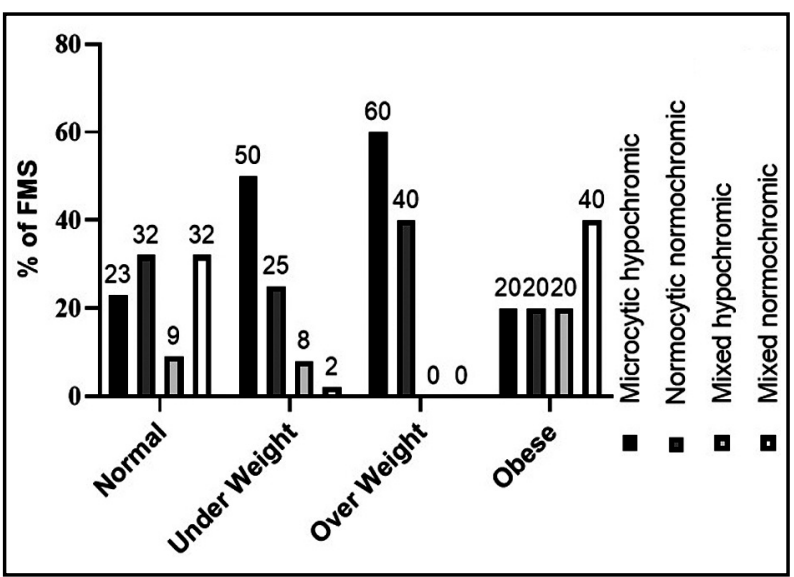

Fig.3: Distribution of morphological types of anaemia by BMI categories of Female Medical Students $n 49$. 
Prevalence of anaemia among female medical students

Table-IV: Association of food groups consumed previous day

by female medical students with their anaemic status $(n=160)$.

\begin{tabular}{|c|c|c|c|c|c|}
\hline \multirow[t]{2}{*}{ Food source } & & \multicolumn{4}{|c|}{ Anaemia status } \\
\hline & & Non anaemic $n(\%)$ & Anaemic n $(\%)$ & Total $n$ & $p$ value \\
\hline \multirow[t]{4}{*}{ Animal-based } & Egg/poultry & $41(49)$ & $42(50)$ & 83 & 0.82 \\
\hline & Fish & $1(100)$ & $0(0)$ & 1 & \\
\hline & Meat & $29(46)$ & $34(54)$ & 63 & \\
\hline & Milk & $48(52)$ & $45(48)$ & 93 & \\
\hline \multirow[t]{3}{*}{ Plant-based } & Green leafy vegetables & $14(63)$ & $8(36)$ & 22 & 0.79 \\
\hline & Fruits & $51(56)$ & $40(44)$ & 91 & \\
\hline & Fresh juices & $20(56)$ & $16(44)$ & 36 & \\
\hline \multirow[t]{2}{*}{ Staple-based } & Cereals & $12(75)$ & $4(25)$ & 16 & 0.99 \\
\hline & Whole grains & $12(75)$ & $4(25)$ & 16 & \\
\hline
\end{tabular}

higher among anaemic FMS in contrast to fish intake (Table IV).

Most of the over-weight anemic FMS presented with microcytic/hypochromic (60\%) and normocytic normochromic blood picture (40\%) indicating higher frequency of micronutrient deficiency among them (Fig.3).

The significant difference was seen between the means of Mentzer index and anaemia markers $(\mathrm{p}=$ $<0.01$ ). The Mentzer index $<13$ (MCV/RBC count) suggests thalassemia trait, and an index of more than 13 suggests iron deficiency. ${ }^{12}$ The four cases were referred for $\mathrm{Hb}$ electrophoresis (Table-V).

\section{DISCUSSION}

Undernutrition is the most common cause of anaemia in Pakistan which is patterned by various factors like age, gender, race, education, dietary habits and physiological state., ${ }^{5,13}$ The female medical students have more understanding and opportunities for anaemia diagnosis and management in context of their educational background and environment. ${ }^{13}$

The FMS self-graded themselves anaemic at individual level factors; age $>19$ years, study year higher than first year but they were not anaemic biochemically. However, FMS with birth order of greater than two were anaemic biochemically as well. Food insecurity is a significant problem at individual-level among university students. ${ }^{14}$ Present study revealed FMS with birth order of greater than two were anaemic biochemically as well. This was in agreement with Harris-Fry $\mathrm{H}$ et al who observed direct relation between the number of family members and food insecurity. ${ }^{15}$ The socioeconomic status was not recognized a significant variable in this study in contrast to recent national survey data. ${ }^{5}$

Present study revealed anemia as a moderate public health issue among FMS; although the FMS had adequate anaemia awareness supported by appropriate self-grading of their anaemia status. This was in agreement with Sam SM, and Uday Kumar PA, 2017; who found inadequate $\mathrm{Hb}$ levels among female medical students despite sufficient knowledge of anaemia. ${ }^{16}$

Majority of the FMS were underweight (35\%) followed by overweight (11\%) and obese (9\%) students. The same trend among young university females of Karachi, Pakistan was also observed by Aziz F. et al. ${ }^{8}$ Various studies reported higher frequency of anaemia among underweight females

Table-V: Distribution of hypochromic microcytic cases by Menzter index to discriminate iron deficiency anemia and $\beta$-thalassemia.

\begin{tabular}{lccc}
\hline Variable & \multicolumn{2}{c}{ Hypochromic microcytic anaemia cases $n=24$} & $p$ value \\
\cline { 2 - 3 } & Mentzer Index $>13 n=20$ & Mentzer Index $<13 n=4$ & $\mathrm{~ns}$ \\
$\mathrm{Hb}(\mathrm{g} / \mathrm{dL})$ & $10.0 \pm 1.3$ & $9.48 \pm 1.2$ & $<0.01$ \\
$\mathrm{RBC}$ count $\left(10^{6} / \mu \mathrm{l}\right)$ & $4.40 \pm 0.3$ & $5.17 \pm 0.36$ & $\mathrm{~ns}$ \\
Hematocrit $\%$ & $33.87 \pm 3.2$ & $32.33 \pm 3.3$ & $<0.01$ \\
$\mathrm{MCV}(\mathrm{fL})$ & $74.80 \pm 5.6$ & $62.61 \pm 5.9$ & $<0.01$ \\
$\mathrm{MCH}(\mathrm{pg})$ & $22.33 \pm 2.5$ & $18.35 \pm 2.0$ & $<0.01$ \\
$\mathrm{Ret}-\mathrm{He}(\mathrm{pg})$ & $25.8 \pm 2.93$ & $15.4 \pm 1.97$ & $<0.01$ \\
$\mathrm{MCV} / \mathrm{RBC}$ count $($ Menzter index) & $17.12 \pm 2.1$ & $12.10 \pm 0.6$ & \\
\hline
\end{tabular}


in Pakistan. ${ }^{4}$ Surprisingly, anaemia among obese FMS was more frequent in present study supported by negative relation between $\mathrm{Hb}$ and $\mathrm{BMI}$ in total FMS(data not displayed). It seems that dietary diversity did not affect the anaemia status of obese FMS. Obesity and iron deficiency are intertwined. ${ }^{2}$ Obesity induced inflammation increases hepcidin (iron metabolism regulating protein) concentrations, resulting in reduced iron absorption in intestine or inhibits iron uptake by ferroportin, a cellular iron exporter, from hepatocytes, macrophages and intestinal cells. ${ }^{17}$ It was supported by higher frequency of microcytic hypochromic and normocytic normochromic anaemia among overweight/obese FMS. Dietary diversity was not associated with the anaemic status of FMS as intake of plant and staple diet by non -anaemic FMS was slightly higher than anaemic FMS except that of meat, poultry and eggs. However, the $\mathrm{Hb}$ level of FMS with low MDD-W score low reflecting its effect on $\mathrm{Hb}$ level. After ruling out Beta thalassemia trait using Mentzer index, low Ret-He in remaining micro/hypo cases indicate iron deficiency. Anemia progressing over a long period may result in IDA and appear as normocytic and normochromic in peripheral circulation. Serum iron and ferritin studies are not indicated in this case with normal Ret-He. ${ }^{5}$

Limitations of the study: The data was collected at a point in time hence not showing dietary diversity over a year. Biochemical evidence of inflammation (like parasitic infections) was not measured in study sample.

\section{CONCLUSION}

Anemia was prevalent among female university students with higher frequency among obese FMS. It was associated with self-assessment of anaemia and BMI groups but not with dietary diversity. This reflects the co-existence of double burden of malnutrition and anaemia despite knowledge related awareness of anaemia in FMS. This could be possible due to lack of diverse diet intake/ knowledge/access and/or obesity.

Acknowledgement: We would like to extend our gratitude to Dr. Sabahat Babar, Dr. Naheed Khan, Dr. Fauzia Imtiaz, Ms. Amber for helping in sample collection and also Mr. Syed Muhammad Salman and Mr. Muhammad Adeel for technical and material support.

Grant \& Financial Support: None.

\section{REFERENCES}

1. Anaemias WN. Tools for Effective Prevention and Control. Alberto March, World Health Organization. WHO Document Production Services, Geneva, Switzerland. 2017; pg 7

2. Hanafi MI, Abdallah AR, Zaky A. Study of hemoglobin level and body mass index among preparatory year female students at Taibah University, Kingdom of Saudi Arabia. J Taibah Uni Sci. 2013;8(3):160166. doi: 10.1016/j.jtumed.2013.04.004

3. Vos T, Abajobir AA, Abate KH, Abbafati C, Abbas KM, Abd-Allah F, et al. Global, regional, and national incidence, prevalence, and years lived with disability for 328 diseases and injuries for 195 countries, 1990-2016: a systematic analysis for the Global Burden of Disease Study 2016. Lancet. 2017;390(10100):1211-1259. doi: 10.1016/S01406736(17)32154-2

4. Jawed S, Tariq S, Tariq S, Kamal A. Frequency of nutritional anemia among female medical students of Faisalabad. Pak J Med Sci. 2017;(2):398-403. doi: 10.12669/pjms.332.11854

5. Yu Z, Blankenship LM, Ibrahim M, Gbadamosi B, Stender M, Anderson J, et al. Does Normal Reticulocyte Hemoglobin Rule out Iron Deficiency as a Cause of Normocytic Normochromic Anemia? Blood. 2016;128(22):4826. doi: 10.1182/blood.V128.22.4826.4826

6. Harding, KL, Aguayo, VM, Namirembe, G, Webb, P. Determinants of anemia among women and children in Nepal and Pakistan: An analysis of recent national survey data. Matern Child Nutr. 2018;14(S4):e12478. doi: 10.1111/mcn.12478

7. Lopez A, Cacoub P, Macdougall IC, Peyrin-Biroulet L. Iron deficiency anaemia. Lancet. 2016;387(10021):907-916. doi: 10.1016/ S0140-6736(15)60865-0

8. Aziz F, Siddiqui B, Jabeen F. Prevalence of Nutritional Anemia's associated with Body Mass Index and Hemoglobin Concentration among Young University Females, Karachi, Pakistan. Sindh Uni Res J (Science Series). 2017;49(4):779-784. doi: 10.26692/sujo/2017.12.0057

9. Ayensu J, Annan R, Lutterodt H, Edusei A, Peng LS. Prevalence of anaemia and low intake of dietary nutrients in pregnant women living in rural and urban areas in the Ashanti region of Ghana. PLoS One. 2020;15(1):e0226026. doi: 10.1371/journal.pone.0226026

10. Cheikh Ismail L, Knight HE, Ohuma EO, Hoch L, Chumlea WC, International Fetal and Newborn Growth Consortium for the 21st Century (INTERGROWTH-21st). Anthropometric standardisation and quality control protocols for the construction of new, international, fetal and newborn growth standards: the INTERGROWTH-21st Project. BJOG. 2013;120:48-55.

11. Misra A, Dhurandhar NV. Current formula for calculating body mass index is applicable to Asian populations. Nutr Diabetes. 2019;9(1):3. doi: 10.1038/s41387-018-0070-9

12. Mousa AO. Types of anemias with low MCV using Mentzer Index and RBC count among patients seen in Basrah Al-Sadir Teaching Hospital. Med J Babylon. 2014;11:292-296.

13. Bharati S, Pal M, Sen S, Bharati P. Malnutrition and anaemia among adult women in India. J Biosoc Sci. 2019:1-1. doi: 10.1017/ S002193201800041X

14. Davidson AR, Morrell JS. Food insecurity prevalence among university students in New Hampshire. J Hunger Environ Nutr. 2018:1-10. doi: 10.1080/19320248.2018.1512928

15. Harris-Fry H, Shrestha N, Costello A, Saville NM. Determinants of intra-household food allocation between adults in South Asia-a systematic review. Int J Equity Health. 2017;16(1):107. doi: 10.1186/ s12939-017-0603-1

16. Sam SM, Udaykumar PA. Does knowledge and increased awareness among our female postgraduate medical students contribute to improve their hemoglobin levels. Asian J Pharm Clin Res. 2017;10(10):347-350. doi: 10.22159/ajpcr.2017.v10i10.20264

17. Haidari F, Abiri B, Haghighizadeh MH, Kayedani GA, Birgani NK. Association of hematological parameters with obesity- induced inflammation among young females in Ahvaz, South-West of Iran. Int J Prev Med. 2020;11:55. doi: 10.4103/ijpvm.IJPVM_35_18

Author's Contribution: AS: Helped in Data collection, Interpretation of results, manuscript writing and is accountable for the integrity of the data. SAQ: Helped in manuscript writing and drafting, reviewed and approved the manuscript. MBA: Helped in statistical analysis, interpretation of results, formulation of tables. Reviewed and approved the manuscript. 